\title{
Editorial: The full spectrum of public health
}

\author{
Ulrich Laaser
}

Published online: 9 January 2009

(C) Springer-Verlag 2009

Since the last decade of the twentieth century we have observed a global renaissance of public health as a major orientation for politicians, donors, activists and health professionals: a focus of debate in civil society. The doors opened with the declarations of Alma-Ata in 1978, the Ottawa Charter in 1986, and last but not least with the Millennium Development Goals in 2001 (http://www.un. org/documents/ga/docs/56/a56326.pdf). Recently two reports have been published underlining the social determination of the health of populations (http://www.who.int/ social_determinants/en/) and the central role of primary health care of high quality not only in developing countries but also in Europe (http://www.who.int/whr/2008/en/index. $\mathrm{html}$ ). Analysing the broad range of public health issues and even more intervening at the population level requires a multidimensional scientific approach. That is why we should speak of the health sciences in the plural: There is no single truth. Especially the aged battle between medicine and the social sciences does not make sense anymore. We coined the term of the double paradigm of public health [Hurrelmann K, Laaser U (1993) Gesundheitswissenschaften als interdisziplinäre Herausforderung. In: Hurrelmann K, Laaser U (eds) Gesundheitswissenschaften, Handbuch für Lehre, Forschung und Praxis. Beltz, Weinheim, pp 3-25], but in fact today we have to accept a multiple paradigm. In conclusion we can speak of a two-dimensional extension of the new public health concept, across the globe and across the traditional disciplines. One step in this process is the 12th World Congress on Public Health: Making a Difference in

U. Laaser $(\bowtie)$

Centre School of Public Health, Medical Faculty,

University of Belgrade,

Pasterova 2,

P.O. Box 5611129 Belgrade, Serbia

e-mail: ulrich.laaser@uni-bielefeld.de
Global Public Health: Education, Research, and Practice (27 April-1 May 2009 in Istanbul, http://www.wfpha.org).

This issue of the Journal of Public Health covers quite a substantial part of the range of public health problems around the world. Communicable diseases especially viral infections are not at all out, on the contrary due to hunger, civil war and weak health systems we have to cope with a number of emerging and re-emerging diseases. As vaccines are still the most important preventive tool we face two restrictive factors: attitudes and costs. The paper by Allaert et al. deals with parents' attitudes towards varicella vaccination and demonstrates by comparing the situation in France and Germany that appropriate information about the potential severity of the disease and the efficacy and safety of the vaccine can overcome any resistance. The paper by Hillemanns et al. analyses the cost-effectiveness of the tetravalent human papillomavirus (HPV) vaccination in the prevention of cervical cancer and genital warts associated with HPV types 6, 11, 16 and 18 .

The next five papers lead us to Burkina Faso in SubSaharan West Africa, to Iran, to the Gaza Strip and to Jordan. Marschall and Flessa investigate the cost-effectiveness or efficiency of rural health centres in Burkina Faso, one of the first economic evaluations of the primary health care sector in Africa. They conclude that instead of closing down inefficient centres transport facilities or accessibility as the main determinants of inefficiency have to be improved. Krieg and Gardemann report on the experience of international aid after the earthquake in Bam, Iran in 2003. Based on more than 16,000 cases they argue for a standardisation of morbidity records in emergency situations. Varasteh et al. report a cross-sectional representative survey on allergic symptoms in the industrial city of Mashdad, North-eastern Iran establishing an overall prevalence of $27.5 \%$. Kanao et al. from the Al-Azhar University in Gaza point to dominant 
regional differences for overweight and nutritional status even within the small territory of the Gaza Strip, where a heterogeneous population of old Gazouis and refugees from 1948 live together under the conditions of one of the highest population densities of the world. Finally Al-Safi et al. can show that the smoking of water pipes or shisha is associated with elevated blood pressures and heart rates.

The issue concludes with three studies from Germany. The first one by Neumann et al. reports the baseline results of a cluster randomised cohort study among almost 2,800 German practitioners on patients with peripheral arterial disease (PAD). Treatment rates seem to have improved in comparison to earlier surveys; however, PAD constitutes a considerable burden in primary health care. Caniato et al. find alarming changes in the pattern of deficits of German schoolchildren regarding motor and speech disorders the causes of which have to be investigated carefully. Becker and ZimmermannStenzel confirm the finding that elderly people who do not exercise regularly are also less active on a day-to-day basis and are less likely to take a walk or ride a bike for transport.

The last paper by Weiss reviews the rationale and prototype for new safety or compliance packaging for over-the-counter (OTC) drug products in the USA that are sold in pill form inside blister packs, e.g. analgesics.

The papers assembled in this issue of the Journal of Public Health are a good example of the wide range of public health problems but also of the stage of scientific advance in countries as different as the Gaza Strip and Germany. As we have to accept the increasing interdependence of developments in different areas of the world and in different fields of expertise, more effort is needed to bring together the full spectrum of public health. 